\title{
Research on the Design Mode of Web Course of Track \&Field in Physical Education in College
}

\author{
http://dx.doi.org/10.3991/ijet.v9i3.3285 \\ Weiliang Lin, Tao Li \\ Guangzhou University,Guangzhou,Guangdong,China.
}

\begin{abstract}
The purpose of this paper is to improve the current condition of students' skill deficiency, relative textbooks and practice guidance. The research methodology includes literature study, interview, system designing, software programming, questionnaire survey and mathematical statistics. Results: Firstly, there are effective contents and practice activity in the web course. Secondly, the purpose and requirements are clear in the course. Thirdly, there is a variety of cases, pictures, videos and texts on the web page. Fourthly, the web course is appealing that it can inspire students to be more imaginative and innovational. Conclusions: the setup of the T\&F Web Course can make up for the initiative and self-directed learning deficiency of traditional classroom teaching, and it also helps to cultivate sport talents who are needed in the society.
\end{abstract}

Index Terms-College physical education, Track and field, Web course, Design mode

\section{INTRODUCTION}

At present, sports web courses have the problems of many content repetitions in teaching, the neglect of constructing learning environment, the lack of construction and guide of study and interactive learning mode, and the lack of improvement in the page visual design[1-3]. Currently the track and field Network teaching mode of college sports mainly contains the websites of single sport science and the auxiliary instruction in T\&F with materials from campus network, and the practical application in the T\&F network course is barely systematically studied, and there is also a lack of enough literature, which are all to the disadvantage of the development of the modern T\&F auxiliary teaching[4-5].

It has become an urgent task to find out how to apply the current advanced network resource to improve the auxiliary teaching of special track and field[6]. The design and management of this network course on track and field help teachers and students interact more easily through the internet at any time, and help the rapid spread of teaching information and real-time communications and help the discovery of the new things in related fields to update the teaching contents to improve the students' capability of analyzing and solving problems[7-8]. This course is also designed to improve the monotonous traditional teaching style[9], students can conduct self-directed learning during the different periods of the network teaching, which makes this network course a very convenient system platform for different students to learn different contents and test themselves at the same time. The design and the application model of this course help teachers and students communicate more conveniently and have already taken some effect in practical application.

\section{STUDY OBJECTS AND METHODOLOGY}

\section{A. Objects}

Take the web course of T\&F in Guangzhou university as a case, study the design mode of this web course under the reform of present physical education.

\section{B. Methods}

Literature study: Consult related books and databases: 《Physical Education Teaching Outline of $T \& F$ in Guangzhou university Physical Culture Institute》;

《Theory and Method of Teaching Training of Track and Field $\rangle$, collect related formation from home and abroad as the reference and basis for the design of the web course.

The interview methods: Gather views and advices from experts and professors from Schools of Computer Science and School of Physical Education. To further analyze the needs of students through interviews to insure the suitableness of the web course contents and the activity contents system.

The system designing methods: According to the requirements of learning theory and targets of practice class teaching, the logical relation between teaching content and its resources decides the self functions of the teaching modules and how they will be bonded organically.

The method of software editing: According to the regulations of 《Modern long-distance resource design technique criterion》, carried out by Ministry of Education in 2000 , the curriculum module of this web course is designed with the WCB courseware, which was developed under the cooperation of Guangzhou university and Nanking Qiaomu Science Ltd, and Flash Premiere and etc.

The web page editor: Its function buttons. Basis function button, the editor buttons of webpage property, insert buttons, file buttons, file import buttons, others buttons (Figure 1).

The compilation of test paper: The layout of compilation page, call out the theme editor ware by pressing "append" or "editor". Use subject editor to compile nine types of questions: Single choice, multiple choices, true of false, fill in the blanks, calculation, short answer questions, cloze and reading comprehension (Figure 2).

The formula editor: Open the formula editor through page editor or subject editor and there are two kinds of formula editor (Figure 3).

The editor of common columns and section page: Users can edit the columns and sections via editor area or open the pages of different columns and click Window menu to 
choose different menu item to design the display mode of the columns in the main window. When the page is in full screen display, users can switch the pages by clicking page tittles in the Window menu.

Importing contents: If users batch transfer the file content into the courseware, right click the common columns or chapters directory and then click Import content in the shortcut menu, and then choose the files that will be imported and set the importing conditions and click Confirm, after the system pops up Confirm, importing is done.

Experts questionnaire survey: On Jan 20, 2013, 20 shares of questionnaires referring to the T\&F network course, which had been handed out to experts in the network center and in T\&F teaching field in Guangzhou University, were all withdrawn, and the withdrawal rate is $100 \%$.

The mathematical statistics: Use SPSS 16.0 statistical software to account the 20 shares questionnaires from the experts of the network center and class teaching in Guangzhou University, it provides empirical evidence for the study.

\section{THE DESIGN OF WEB COURSE CONTENT IN TRACK AND FIELD}

\section{A. The basic requirements of the web course}

Teaching Methodology: The teaching methods are embodied in this web course[10]. Practice the key points like sport skills, referee rules, training, internship and employment, and enhance the understanding of practice course through asynchronous learning, simplifying texts, watching video and pictures on line (Figure 4).

Teaching calendar: The teaching calendar includes a one year teaching calendar from school, the teaching schedules from different grades' students in this semester, which reflect the situation of teaching schedule about T\&F compulsory courses, selected courses, minor courses of the students of different grades in physical education School.

Teaching syllabus: The teaching syllabus is the syllabus of $T \& F$ required course, selected course and minor course in physical education. The syllabus adopts the school audited teaching syllabus of track and field as raw material; students can check the requirements of correspondent syllabus of T\&F at any moment.

The electronic teaching materials: The electronic materials avoid repeating the same materials in the schoolbook in $\mathrm{T} \& \mathrm{~F}$ for the semester, instead, it provides some other $\mathrm{T} \& \mathrm{~F}$ related materials, such as $\mathrm{T} \& \mathrm{~F}$ teaching, training, referee and physical ability, so as to make up for the oneness of the present schoolbook, and it's advanced, scientific and readable.

\section{B. School works and test questions}

School works have a required course exercise, selected course exercise, a minor course exercise in the T\&F. A certain amount of exercise is selected in $T \& F$ course for different grades' students, such as the exercise from Track and field, by Liu Jianguo, for the required course of T\&F, Advanced book of T\&F athletics, by Wen chao, for the selected course of T\&F, T\&F Practical Course, by Liu Yongdong, for the minor course of T\&F.

Test questions are mainly about the $\mathrm{T} \& \mathrm{~F}$ theories from required course, selected course and minor course, and

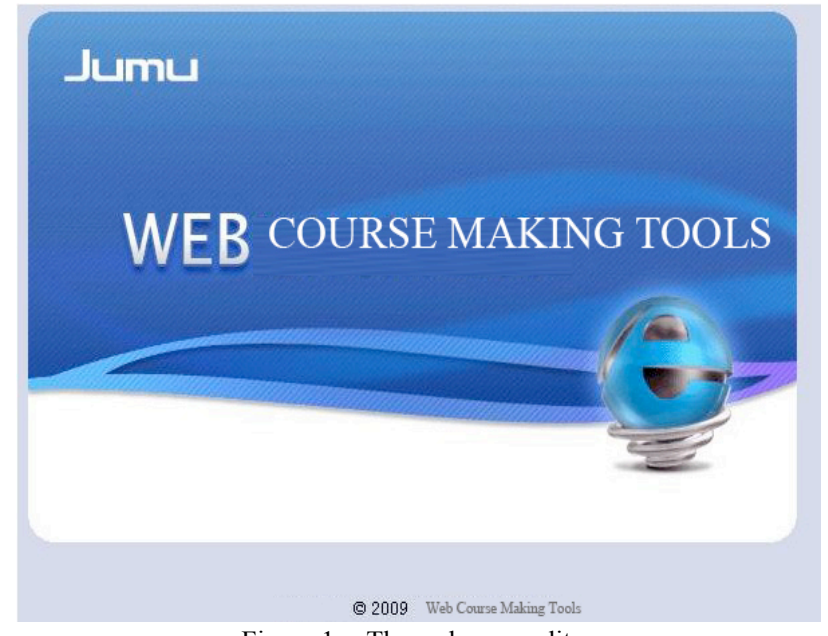

Figure 1. The web page editor

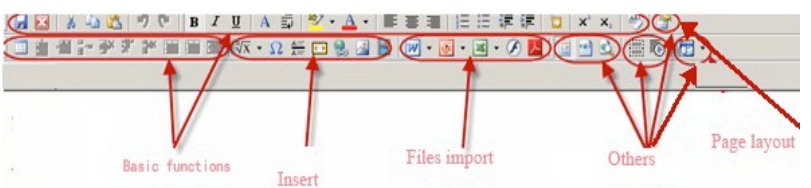

Figure 2. The Blending Editor Ware

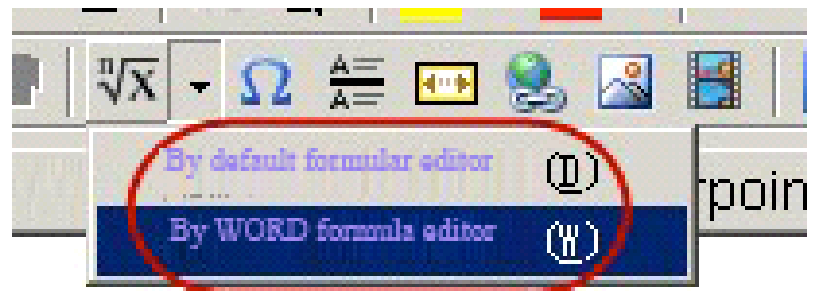

Figure 3. The Formula Editor

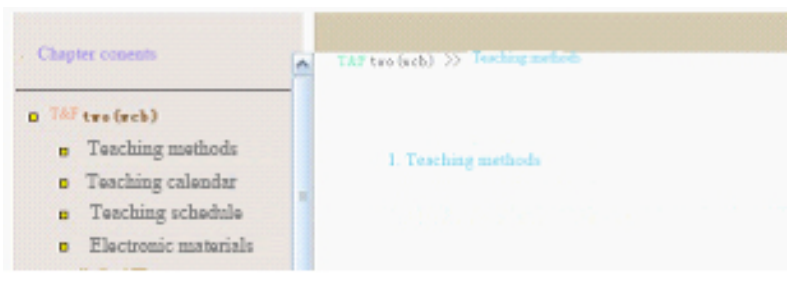

Figure 4. Teaching Methods

there are also simulation test papers about $T \& F$ referee. There are many question types: single choice, multiple choices, cloze, true and false, conception analysis, short questions, essay questions, drawing and etc. The test questions can be answered repeatedly and students can test themselves, when giving a wrong answer, the students will be informed and given learning suggestions or advice the student to study the chapter again.

\section{The practice guidance of $T \& F$}

$T \& F$ training: The training of $\mathrm{T} \& \mathrm{~F}$ includes training methods, training plans, training session principles, precompetition training and regulation; some pre-competition training cases of students who take part in important T\&F events and some after school training cases are combined with $T \& F$ theory as the web page contents, which enrich the training theme with pictures and explanations.

The T\&F referee: The T\&F referee contains the recent reform rules of referee theory, the referee field operation process of every item in T\&F. Use students' after school 
officiating experience as material, like school T\&F games, elementary and secondary school T\&F games, enterprise T\&F meetings, to deepen the students' understanding of the officiating rules, make the particulars of amendment of the $T \& F$ referee rules public timely is the essential information. The brief text and pictures of this kind of information.

The T\&F game events: The T\&F game events adopt the videos of related race events from this school and also from higher level game events at home or abroad. It also updates the games timely and preserves the documents and comments of the games, which not only makes it easier for students to enjoy and follow games, but also can improve students' ability of analyzing the skill differences in games of different level. It also provides download services for teachers for their off-line teaching.

The classroom teaching of T\&F: The classroom teaching of T\&F includes the teacher' theories, practice lesson and open classes, of which the PPT can be used as selflearning material, teachers' demonstration on class and their open class are very good materials for students to simulate. All these templates are displayed in brief texts, pictures and multimedia.

The after school practice guidance: The after school practice is subject to $\mathrm{T} \& \mathrm{~F}$ teaching, after school training guidance and supervisor's work materials. The basic requirements before practice: queue organization, teaching plans and teaching practice. During practice, it contains the standard of behavior in the school, the classroom teaching mode, training guidance, the referee work of track and field meeting during practice, the work of class supervisor. Students' final report after practice, all these materials above mentioned are displayed with brief text and pictures in the web course.

The T\&F research guidance: The T\&F research guidance is mainly for the graduating students who are in need of writing their dissertations, and it reflects the F\&T related social concerns, displays materials or problems on T\&F teaching, training, officiating and physical capability which are to be solved or further studied. The materials of format, word number and the maneuverability of dissertation writing are all from the paper samples in the past years, which can be of great guidance to graduating students.

The T\&F career guidance: This section provides analysis on the present's social employment demands for teaching, training and diathesis in $\mathrm{T} \& \mathrm{~F}$, and the related qualifications for applying for jobs in middle and primary schools: long jump, half of the hurdles, high jump, stuffed ball throwing, organizing ability in T\&F teaching, application of $\mathrm{T} \& \mathrm{~F}$ training methods, civil servant and police sport quality test, so as to deepen students' understanding of the present requirements of the society.

The health knowledge of T\&F: Another character of $\mathrm{T} \& \mathrm{~F}$ web course is that it has an extension from class teaching, i.e. providing related knowledge of T\&F. As teachers-to-be, the students of physical education need to know comprehensive knowledge on $\mathrm{T} \& \mathrm{~F}$, especially to know how to realize safe teaching, avoiding injury in the process of exercising, and self-protection after practice, such as the prevention and management of injury and exercise prescription. And strengthen the protection consciousness of vulnerable body part of students during practice through displaying brief texts, pictures and injury cases in teaching and training in this module[11].

A list of celebrities in track and field: The list mainly tells moving stories of stars of track and field at home and abroad with brief texts and their pictures. These famous athletes attained excellent results through their endeavors in the history of $\mathrm{T} \& \mathrm{~F}$, which are very inspiring.

\section{T\&F video section}

This section mainly contains videos of training, officiating, events, classroom, and practice after school and so on. Training reflects the levels of training after school, it contains videos from training of on-campus and off-campus pre-competition. For example, videos from on-campus T\&F sport meeting, provincial university sport meeting, and national basic skill contest. The officiating videos are from students' after school officiating practice in oncampus and off-campus F\&T meetings, which show the different procedures of different events and the cooperation of referees. The events videos are from school T\&F meeting, provincial university students F\&T games or F\&T championships at home and abroad. The skill materials in classroom teaching are from the students' standard skill demonstration, common technical difficulties and some good exercise methods. The videos of after school practice are from the teaching practice and training practice in their specified practice schools (Figure 5).

In the teaching videos, its emphasis is on the segment of technology action, dynamic to static, rapid to slow[1213]. Make use of materials of teachers' classroom teaching, students' practice teaching and the elite players' demonstrations at home and abroad. All materials were edited by web courseware and further edited by video converter.

Every technical teaching segment was designed to have the function of cycle play, normal speed, slow speed, fast speed, suspended demonstration of key skill[14-15]. It is easy for students to control the player with buttons when needed. The audio of this web course operates through collecting sound to generate WAV file by sound card and microphone in computer. The background music was edited to sound source of CD or VCD with professional software such as Leawo Video converter.

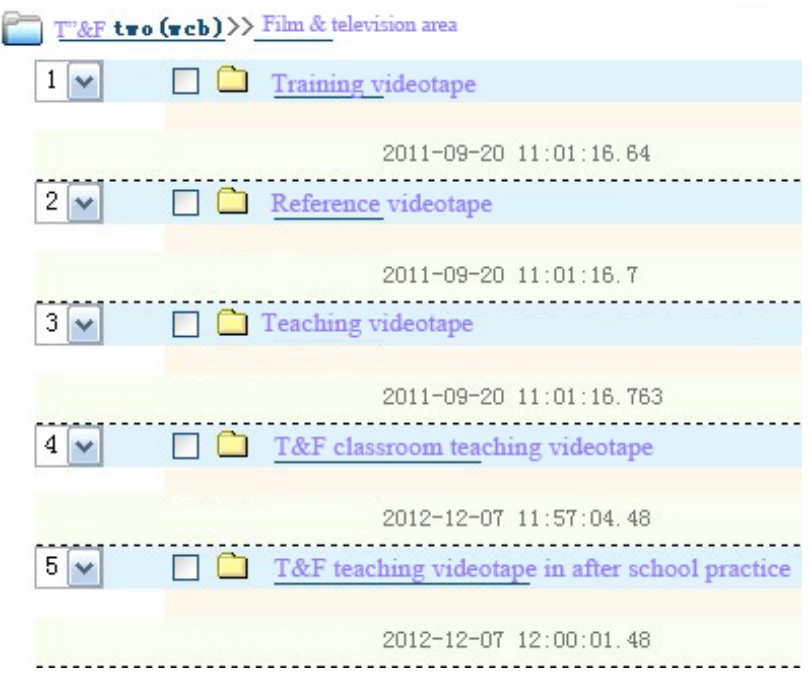

Figure 5. The Total Structure Diagram of Film And Television Area 


\section{RESULTS AND ANALYSIS}

\section{A. Results}

The application of the design on $T \& F$ web course: As show in Figure 5, 70\% of experts consider that learners can apply the knowledge of the web course to the teaching practice flexibly, while only $30 \%$ think they can achieve that. It shows that the structure content of the web is very effective, in which provides practice activities (Figure 6).

The basic requirements of $T \& F$ web course: In the basic demands of T\&F web course, $60 \%$ of the experts agree that there is a very clear basic demand and learning target, while $40 \%$ think it is clear. As shown in Figure 6. I.e. there are clear learning targets and teaching requirements: teaching calendar, teaching syllabus, the electronic materials and so on. And they are displayed in the chapters (Figure 7).

The teaching resources of T\&F web course: $100 \%$ of the experts deem that the teaching resource displays variety in the $\mathrm{T} \& \mathrm{~F}$ web course, i.e. the page layout has a variety of cases, pictures, videos, texts and so on.(Figure 8).

The teaching record in classroom: As show in Figure 9, $85 \%$ of the experts consider that it attracts the students and develops the creative thinking of the students; $15 \%$ holds a positive attitude. Generally, the teaching record is infectious; it attracts students and develop the their creative thinking ability.

\section{B. Analysis}

Analysis of the basic properties of $T \& F$ : The teaching methods can help students use the web course more consciously, and take part in the asynchronous learning more actively. Teaching calendar helps student get better informed with the teaching periods, the holidays, the important school activities, festivals, and the teaching schedule of T\&F required course, selected course, minor course for the students in physical education. The teaching targets, contents, the standard of examination of the teaching syllabus, the teaching contents and class hours in different semesters are displayed on the web course with illustrating pictures for students to follow their schedules and to achieve their goals. The electronic textbooks enrich the T\&F study and theoretic knowledge out of textbooks, which is economical and practical.

Analysis of the school works and test questions: In the process of T\&F teaching, tests can check students' learning result and help them get a better command of the knowledge; different kinds of school works are good for the students' memory of the knowledge. This web course has a "test questions" column which is easy for the students to submit the test papers of T\&F theory, and the web system will automatically grade them and students can get the feedback right away and get to know their evaluations.

Analysis of the practice guidance: In the teaching syllabus of required courses, the total number of class hours is 64 , training, officiating, classroom teaching occupy $0.03 \%$ of total hours respectively; the class hours of $\mathrm{T} \& \mathrm{~F}$ required class is 192 , training, officiating, classroom teaching, science research take $0.02 \%$ of the total respectively; $\mathrm{T} \& \mathrm{~F}$ minor course has 64 class hours, and officiating and classroom teaching take $0.05 \%$ of the total respectively. That reflects the limit class hours and the absence of offcampus practice, T\&F health knowledge, T\&F employment, T\&F list of celebrities. The practice guidance of

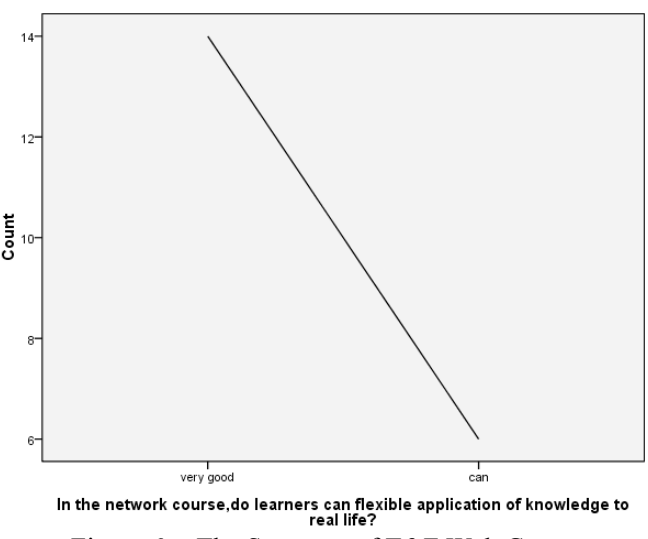

Figure 6. The Structure of T\&F Web Course

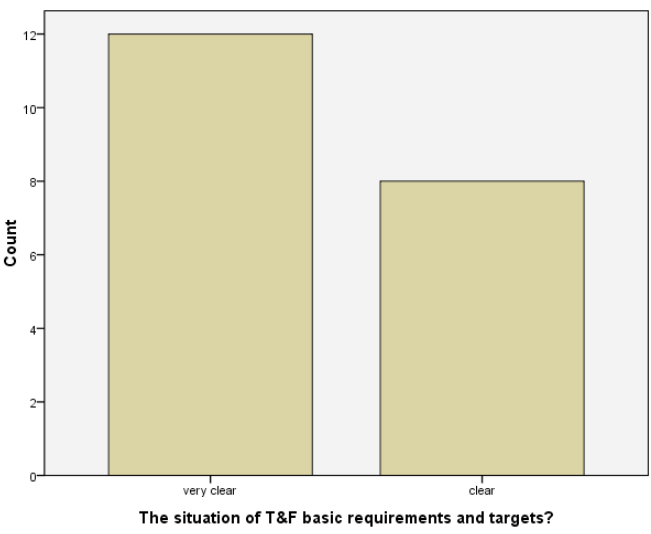

Figure 7. The Basic Demands of The Web Course

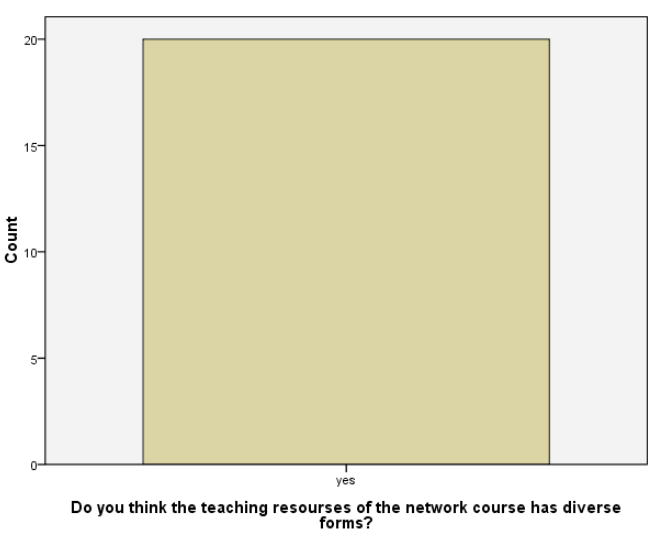

Figure 8. The Teaching Resources of T\&F Web Course

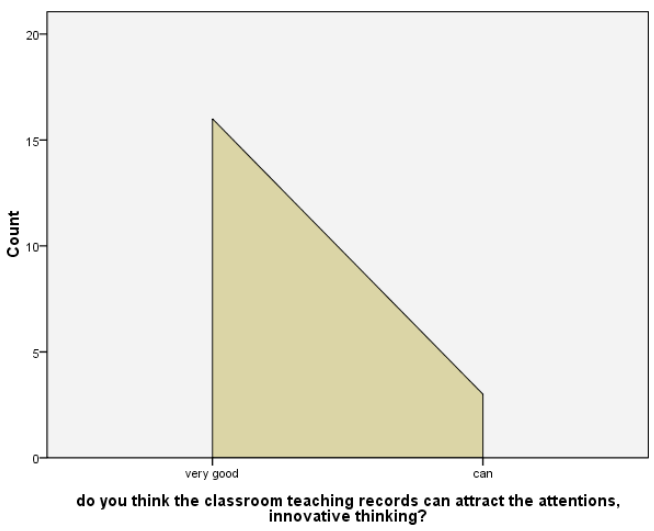

Figure 9. The Teaching Record of Classroom 
T\&F web course makes up for the shortage of the traditional teaching, such as the decrease of class hours, big skill difference and large number of students, and the limited condition of classroom teaching. And this web course also caters to needs of talents in the society. So it is really important to include the modules of F\&T training, officiating, events, classroom teaching, after school practice, research, health knowledge base, celebrity list and career guidance in the $\mathrm{T} \& \mathrm{~F}$ practice guidance[16].

Analysis of the video section: The video section contains training, officiating, game events, classroom teaching, off-campus practices, these videos were edited according to the needs of teaching contents in $\mathrm{T} \& \mathrm{~F}$, and it use students' experiences of training, officiating, game events, classroom teaching, off-campus practices, plus some skills of high level athletes from home and abroad and officiating organization of important events, to help students get the whole picture of T\&F games.

\section{CONCLUSIONS}

This design of T\&F web course can make up for the deficiency of the traditional classroom teaching by inspiring the learner's enthusiasm and mobilizing their self-learning initiatives, it also caters to the needs of sport talents in society. The diversity, practical applicability of its contents are the results of the $\mathrm{T} \& \mathrm{~F}$ teaching reformation and this web course is the very innovational result that meets the need of the development of T\&F classroom teaching.

\section{REFERENCES}

[1] Wu Xiao, "Study on the Web construction from Physical college's course teaching", Journal of Anhui physical science, vol. 4, no. 30, pp. 83-85, 2009.

[2] Chen Xiaoping, "The teaching model was reformed with the techniques of modern internet", Journal of Liberation physical college, November 2000.

[3] Cha Chunhua, Zhang Baohua, "Research on Web course's designs of bonny gym base on resource study", Journal of Capital physical college, vol. 2, no. 19, pp. 142-146, 2007.

[4] Zhang Jian, "Explore on the internet course design of computer brainpower in the field of college physical", Journal of Zhejiang physical science, vol. 3, no. 27, pp.78-80, 2005.

[5] Zhang Xueliang, "The development of CAI courseware and internet teaching from college physical", Journal of Tianjin university, vol. 1, no. 2,2002 .
[6] Dewan, S., \& Dewan, D. "Distance Education Teacher as a Leader. Learning from the Path Goal Leadership Theory", MERLOT Journal of Online Learning and Teaching 2010.

[7] Shea, P.,\& Bidjerano, "T. Learning Presence: Theory of SelfEfficacy, Sef-Regulation, and the Development of a Communities Of Inquiry in Online and Blended Learning Environments", Journal of Computers \& Education, vol. 55, pp. 1721-1731, 2010. http://dx.doi.org/10.1016/j.compedu.2010.07.017

[8] Arbaugh, J.B. Sage, "Guide, Both, or Even More? An Examination of Instructor Activity in Online MBA Courses", Journal of Computers \& Education, vol. 55, pp. 1234-1244, 2010. http://dx.doi.org/10.1016/j.compedu.2010.05.020

[9] Wang Wenjun, Huang Zhiwu, "The design and development of web course in physical education of higher school", Journal of Beijing sports university, vol.10, no. 29, pp. 1416-1417, 2006.

[10] [10 ]Mao kun, Zhan Jing, Yang Aidong, "The Design of College Physical Education”, Journal of Beijing sport university, vol 3 , no. 28, pp. 380-409. 2005.

[11] Gong Zhengwei, Xujun, " Study on the development model of web course of school physical base on the background of distance education”, Journal of Capital physical college, vol. 2, no. 20, pp. 87-90, 2008.

[12] Guo Hong, Huang Yushan, Deng Shuxun, Zen Fan, "The design on Web course from sport body science”, Journal of physical science, vol. 2, no. 21, 2001.

[13] Cao Zhenfeng, "The internet design of good course base on biodynamics of ASP. NET", Journal of Hubei Wuhan physical college, vol.3, pp. 22-26, Jan 2010.

[14] Perumalla, J.Mak, N. Kee, S. Matthews, "Integreating web applications to provide an effective distance online learning environment for students," Procedia computer science, vol. 3, pp. 770784, 2011.

[15] Kulthida Nugultham, "Using Web 2.0 for innovation and information technology in education course," Preocedia-social and behavioral sciences, no.46, pp.4607-4610, 2012.

[16] Erman Uzun, M.Yasar Ozden, "Determining new instructional strategies for web design course in vocational education with respect to instructional technology perspective," Precedia-social and behavioral sciences, no.47, pp. 426-432. 2012.

\section{AUTHORS}

Weiliang lin is with the School of Physical Education and Sports Science of Guangzhou University, Guangzhou, China (Linweiliang70@163.com).

Tao $\mathbf{L i}$ is with the Track and field department of Guangzhou physical and culture education college, Guangzhou, Guangdong, China (gtlitao@163.com).

The research was supported by the research fund of Guangzhou University, China (Grant No.0L1009322). Manuscript received 1 April 2013. Published as re-submitted y the authrs 18 May 2014. 